\title{
O PERFIL PSICOSSOCIAL DE CRIANÇAS E ADOLESCENTES VÍTIMAS DE VIOLÊNCIA SEXUAL
}

\section{The psychosocial profile of children and adolescents victims of sexual violence}

\section{Dayane Monteiro da Silva- Centro Universitário Fametro/Brasil}

RESUMO: A violência é algo que perpassa a história da humanidade, sendo observada em diversos contextos sociais. A violência sexual acarreta traumas e sofrimento para suas vitimas, principalmente crianças e adolescentes. Este trabalho teve como objetivo investigar o perfil psicossocial de crianças e adolescentes vítimas de violência sexual, os fatores de risco que provocam esse crime e os possíveis desdobramentos emocionais e psicológicos acarretados pelos abusos. Esta pesquisa teve uma abordagem quantitativa, cunho descritivo e documental, com dados dos sumários do setor psicossocial da Delegacia Especializada na Proteção de Crianças e Adolescentes (DEPCA) no estado do Amazonas/AM. Os resultados apontam que os fatores de risco que propiciam a violência são múltiplos, como a faixa etária da criança, o gênero, as questões educacionais da família, falta de comunicação no contexto familiar, desemprego, dificuldades conjugais, responsáveis passivos, famílias recompostas. A análise dos documentos demonstraram que as crianças vítimas de abusos sexuais apresentaram alterações físicas, psíquicas, emocionais, comportamentais, sociais, anormalidades sexuais, prejuízo escolar.

Palavras-chaves: Violência sexual, crianças, adolescentes, perfil psicossocial.

ABSTRACT: Violence is something that permeates the history of humanity, being observed in various social contexts. Sexual violence causes trauma and suffering for their victims, especially children and adolescents. This study aimed to investigate the psychosocial profile of children and adolescents victims of sexual violence, the risk factors that cause this crime and the possible emotional and psychological consequences of the abuse. This research had a quantitative approach, descriptive and documentary, with data from the psychosocial sector summaries of the Specialized Police Station for the Protection of Children and Adolescents (DEPCA) in the state of Amazonas / AM. The results indicate that the risk factors that lead to violence are multiple, such as the age of the child, gender, family educational issues, lack of communication in the family context, unemployment, marital difficulties, passive guardians, recomposed families. The analysis of the documents showed that children who were victims of sexual abuse presented physical, psychic, emotional, behavioral, social changes, sexual abnormalities, school impairment.

Key-words: Sexual violence, children, adolescents, psychosocial profile.

\section{INTRODUÇÃO}

Educação, Psicologia e Interfaces, Volume 4, Número 1, p. 144-159, Janeiro/Março, 2020.

ISSN: 2594-5343. DOI: https://doi.org/10.37444/issn-2594-5343.v4i1.194 
A violência é algo que perpassa a história da humanidade, sendo observada em diversos contextos sociais. Essa violência pode se apresentar de muitas maneiras, prejudicando de forma direta ou indireta, o sujeito e a sociedade. Para Minayo (2006, p.15) “a violência não é uma, é múltipla. De origem latina, o vocábulo vem da palavra "vis", que quer dizer força e se refere às noções de constrangimento e de uso da superioridade física sobre o outro."

A brutalidade e traumas deixados pelos abusos sexuais têm como principais vitimas as crianças e os adolescentes. Com base nesta questão, o presente estudo teve como objetivo investigar o perfil psicossocial de crianças e adolescentes vítimas de violência sexual, tendo em vista que o assunto ainda é cercado de tabus, medos, silêncio e até mesmo de descaso por uma parcela da população brasileira.

Desta forma levantou-se a possibilidade da realização da pesquisa na Delegacia Especializada na Proteção a Crianças e Adolescentes (DEPCA), onde são atendidos os casos de abuso sexual com crianças e adolescentes. Os casos de crimes contra crianças e adolescentes, como violência física, psicológica, abuso sexual, exploração do trabalho infantil são denunciados na DEPCA, onde as vítimas são atendidas pelo setor psicossocial.

A partir dessa temática, elaboraram-se os seguintes problemas para a pesquisa: Qual o perfil psicossocial das crianças e adolescentes vitima de violência sexual? Quais os fatores de risco que propiciam a violência sexual contra crianças e adolescentes?

A escolha do tema desta pesquisa surgiu pelo alto índice de casos envolvendo a violência sexual contra crianças e adolescentes, no Brasil. Considera-se ainda o fato desta pesquisadora atuar na DEPCA, oportunidade que se deparou com tal fenômeno social.

Nos resultados desta pesquisa serão verificados resultados importantes quanto ao perfil psicossocial das crianças que sofreram abuso sexual, na cidade de Manaus. Tais resultados servirão como um alerta para outras famílias que estejam vivendo essa situação, bem como servirá de base para profissionais da saúde que tratam desse assunto.

\section{MATERIAL E MÉTODO}

Esta pesquisa teve uma abordagem quantitativa, cunho descritivo e foi realizada em campo. Para Marconi e Lakatos (2003, p.187) a pesquisa quantitativa tem como 
finalidade "o delineamento ou análise das características de fatos ou fenômenos, a avaliação de programas, ou o isolamento de variáveis principais ou chave", caracterizados por dados estatísticos para a verificação das hipóteses.

Na pesquisa descritiva, como afirma Cervo, Bervian e Silva (2007, p. 61) o pesquisador "observa, registra, analisa e correlaciona fatos ou fenômenos (variáveis) sem manipulá-los. Procura descobrir, com maior precisão possível, a frequência que um fenômeno ocorre, sua relação e conexão com outros [...]". Para os mesmos autores, esse tipo de pesquisa em suas variadas formas, trabalha com informações ou fatos coletados da própria realidade.

A coleta dos dados deste trabalho foi realizada por meio de uma pesquisa documental, efetuada nos arquivos do setor psicossocial da DEPCA/AM. Esse tipo de pesquisa apresenta-se como um instrumento para coleta e obtenção dos dados. Os dados disponibilizados na ficha das vitimas servirão como roteiro para coleta dos dados. Para Cervo, Bervian e Silva (2007, p.62) "na pesquisa documental são analisados documentos com o objetivo de descrever e comparar usos e costumes, tendências, diferenças e outras características, e utilizam-se materiais que não obtiveram tratamento analítico”.

Quanto aos procedimentos para coleta de dados, após a aprovação do projeto pelo Comitê de Ética, por meio do Parecer n ${ }^{\circ} 3.251 .497$, de 08 de Abril de 2019 a pesquisadora foi à DEPCA, nas segundas e quartas-feiras, nos meses de abril e maio de 2019, no horário das $13 \mathrm{~h}$ as $18 \mathrm{~h}$, para coleta de dados. A pesquisadora realizou sua pesquisa na sala onde se concentram as fichas.

Para a análise dos dados utilizou-se da estratégia estatístico-descritiva. Para Marinho (1980, p. 66 Apud CERVO et al. 2007, p. 67) “depois de coletados e tabulado os dados e expostos em tabelas de forma sintética, eles devem ser submetidos ou não, conforme o caso, ao tratamento estatístico."

Quanto à ética, a pesquisadora seguiu todos os procedimentos relacionados à ética, estabelecidos na Resolução $\mathrm{n}^{\circ}$ 466, de 12 de dezembro de 2012, com a finalidade de não infringir qualquer aspecto dessa resolução. Não será divulgado qualquer nome existente nas fichas analisadas ou dados de identificação das crianças e adolescentes que farão parte da pesquisa. Esta pesquisa foi iniciada somente após a publicação do parecer de aprovação do Comitê de Ética. 
Para a construção da pesquisa foram coletados os dados das crianças na faixa etária de 2 a 12 anos, atendidas no setor psicossocial da DEPCA-AM, no ano de 2018. A amostra desta pesquisa foi de 100 fichas as quais foram analisadas individualmente. Ressalta-se que a escolha pela faixa-etária deve-se a informação, a partir de leitura de materiais específicos sobre o assunto, de que essa faixa-etária tem maior prevalência nos casos de violência sexual no Brasil, como também na instituição vigente. As informações serão coletadas nos arquivos da instituição, dos atendimentos realizados com as crianças no ano de 2018.

Como critérios de inclusão desta pesquisa estabeleceram-se: 1) Crianças e adolescentes que se encontrem na faixa-etária de 2 a 12 anos; 2) As fichas dos casos que ocorreram no ano de 2018; 3 ) As que foram atendidas no setor psicossocial da delegacia.

Como critérios de exclusão foram estabelecidos: 1) os arquivos de adolescentes na faixa-etária de 13 a 18 anos; 2) Os casos que tem classificação confidencial do órgão; 3) As fichas que estão, por algum motivo, ilegíveis; e 4) As fichas de casos que deram entrada no setor psicossocial da DEPCA antes de 2018 e em 2019.

A partir desse delineamento foi conduzida a pesquisa de campo e obtidos os resultados para posterior analise e discussão, como será apresentado a seguir.

\section{RESULTADOS E DISCUSSÃO}

É importante destacar que o presente estudo teve como objetivo caracterizar o perfil psicossocial de crianças e adolescentes vítimas de violência sexual, os fatores de risco que propiciam tal violência e os possíveis desdobramentos psicológicos e emocionais. Os dados apresentados foram coletados nos sumários do setor psicossocial da Delegacia Especializada na Proteção de Crianças e Adolescentes (DEPCA) no estado do Amazonas/AM.

As informações equivalem à coleta de 100 formulários dos casos denunciados e com inquéritos policiais abertos no ano de 2018. A proporcionalidade dos dados evidenciam a magnitude da violência sexual contra crianças e adolescentes. Vejamos a seguir os itens averiguados e analisados a respeito do assunto.

\subsection{Faixa-etária}

Educação, Psicologia e Interfaces, Volume 4, Número 1, p. 144-159, Janeiro/Março, 2020.

ISSN: 2594-5343. DOI: https://doi.org/10.37444/issn-2594-5343.v4i1.194 
Quanto à faixa etária das crianças que são vítimas de violência sexual, verificouse que $62 \%$ dos casos acontecem de 5 a 10 anos, $12 \%$ dos 2 a 4 anos, $26 \%$ dos 11 a 12 anos. Com relação à faixa etária de crianças e adolescentes vítimas de violência sexual, há uma predominância dos abusos em crianças na faixa de 5 a 10 anos.

Nesta faixa-etária as crianças são muito vulneráveis física e psicologicamente ao agressor. Para Vieira (2015, p.266) "a violência sexual afeta sujeitos que, na maioria das vezes, não conseguem verbalizar suas apreensões, seus sofrimentos, ou seja, são vulneráveis aos adultos.” Em complemento, Pfeiffer (2003) apud Soares et al (2016), comenta que fora a relação de poder para com a criança, o agressor aproveita-se da confiança que a mesma tem nele.

Constata-se, portanto, que a faixa-etária de 5 a 10 anos é a mais propensa quanto a esse tipo de agressão em face da vulnerabilidade. Sendo uma característica a ser considerada para aumento dos cuidados com crianças para não se tornarem vitimas de abusos ou violência sexual.

\subsection{Gênero}

Com relação ao gênero de crianças que são vítimas de abusos sexuais, $86 \%$ das vítimas são meninas e 14\% são meninos. Percebe-se que os abusos sexuais são cometidos em maior incidência no gênero feminino. Apesar disso, o gênero masculino também sofre com a violência sexual, mesmo que seja em menor incidência. Dessa forma, verifica-se que a violência sexual de gênero perpassa pela construção sociocultural patriarcal a qual defende relações de dominação a partir de papéis atribuídos a homens e mulheres. Com esse posicionamento, Spaziani e Maia (2017, p.2) comentam que

[...] a violência sexual contra meninas não são exceções, mas sim casos corriqueiros acarretados pelas desigualdades de gênero entre homens e mulheres. A naturalização de ações misóginas e sexistas se expressam cotidianamente por meio da culpabilização da vítima de violência sexual; das piadas e deboche com essa violência; da transmissão de cenas de estupro em filmes e programas televisivos de modo banalizado [...].

Um estudo descritivo do perfil epidemiológico das violências sexuais contra crianças e adolescentes notificado pelos serviços de saúde, no período de 2011 a 2017, realizado pela Secretaria de Vigilância em Saúde e Ministério da Saúde (2018, p.3),

Educação, Psicologia e Interfaces, Volume 4, Número 1, p. 144-159, Janeiro/Março, 2020.

ISSN: 2594-5343. DOI: https://doi.org/10.37444/issn-2594-5343.v4i1.194 
apresentou que "43.034 (74,2\%) eram do sexo feminino e $14.996(25,8 \%)$ eram do sexo masculino".

A partir dessa discussão, pode-se afirmar que a questão de gênero é um fator que contribui para a violência sexual, tendo em o constructo cultural, social dos papéis desempenhados por cada gênero, onde as mulheres tem que assumirem um papel de submissão frente à figura do homem.

\subsection{Crianças que estudam}

Das crianças que foram vítimas de violência sexual, 94\% estudam e $6 \%$ das crianças não estudam. A maior proporção das crianças do presente estudo encontrava-se inseridas na escola, e algumas delas não estavam estudando.

Com base nesses dados, verifica-se a escola como uma possível colaboradora na disseminação de informações junto às crianças e aos pais no que tange a questões relativas à violência sexual. Visto que a maior parte das crianças está estudando, tem-se na escola um meio para a prevenção e a identificação da violência sexual contra crianças, tendo em vista, que a mesma é uma das portas de entrada no reconhecimento de alterações comportamentais, físicas, emocionais. Ponce e Neri (2015, p 337), afirmam que a escola, enquanto Instituição deve ter "[...] o seu compromisso com a construção da dignidade humana, com o cuidado, com a proteção do sujeito, com a construção de uma convivência democrática e solidária entre os seres humanos [...]"

Dessa maneira, pode-se buscar nas escolas uma instituição que poderá contribuir para o combate da violência sexual de crianças e adolescentes, bem como contribuir com as denúncias e revelações para os responsáveis.

\subsection{Direito violados}

No que se refere aos direitos à dignidade e respeito das crianças vítimas de violência sexual, constatou-se que $100 \%$ tiveram seus direitos violados. Os direitos de todas as crianças vítimas de violência sexual do presente estudo foram violados de alguma maneira, direito à vida, saúde, dignidade, liberdade. A violência sexual é considerada como um problema de saúde pública e é designada como uma afronta aos direitos humanos, principalmente, quando as vitimas são crianças e adolescentes. 
Soares et al. (2017, p.735) comentam que "embora a legislação estabeleça a obrigatoriedade da proteção e garantia de direitos de crianças e adolescentes, o Brasil apresenta as maiores estimativas de maus-tratos no mundo nesta fase".

Verifica-se, assim, que as legislações, leis que servem para representarem a proteção da criança, não são garantias que os direitos das crianças não serão violados.

\subsection{Violência sexual}

Com base nos documentos da pesquisa verificou-se que $100 \%$ das crianças sofreram abusos sexuais. É importante destacar, que esse crime é algo que vem assolando a infância e adolescência, para compreensão desse fenômeno é necessário o entendimento dos fatores econômicos das famílias das vítimas como o desemprego, os aspectos culturais da região em que o índice de violência é elevado. A questão cultural patriarcal da dominação da figura masculina e a submissão da mulher, a efetividade de políticas públicas voltadas para o enfrentamento desse problema. Sobre as questões culturais que viabilizam a violência sexual contra crianças e adolescentes, uma pesquisa realizada pelo Instituto de Assistência à Criança e ao Adolescente Santo Antônio - IACAS (2019), apontou que casos de gravidez na adolescência em que se considera que não houve violência física ou que o pai assumirá o bebê e casará com a menina não são considerados como crimes. Assim, ocorre um apaziguamento das medidas que devem ser tomadas pelas instituições de proteção a criança a pedido das famílias envolvidas.

Outro ponto é a naturalização com que é tratado o casamento infantil, algo verificado na esfera institucional, como social.

De acordo com os dados da Secretaria de Vigilância em Saúde e Ministério da Saúde (2018), as notificações de violência sexual contra crianças e adolescentes se concentraram nas regiões Sudeste $(41,8 \%)$, Sul $(24,6 \%)$ e Norte $(12,7 \%)$. Embora, o número de notificações da região norte seja a menor, esses dados são preocupantes, pois as questões de violações de direitos de crianças podem ser consideradas como um fator normal, inserida nas questões culturais, principalmente, em comunidades indígenas e ribeirinhas.

Dessa forma merece um olhar peculiar, para mobilização, conscientização da comunidade para que seja possível o combate e o enfrentamento desse fenômeno.

Educação, Psicologia e Interfaces, Volume 4, Número 1, p. 144-159, Janeiro/Março, 2020.

ISSN: 2594-5343. DOI: https://doi.org/10.37444/issn-2594-5343.v4i1.194 
Diante disso, pode-se dizer que mesmo que a violência sexual contra crianças seja crime, existe a naturalização de determinadas situações que violam a infância que dificultam o combate e enfrentamento desse problema.

\subsection{Vínculo com o agressor}

Com relação ao vínculo com o agressor, verificou-se que 36\% dos agressores eram pessoas próximas das crianças, $28 \%$ padrastos, $14 \%$ pai, $10 \%$ parentes, $6 \%$ avô, $4 \%$ desconhecidos, $2 \%$ irmão. No que se refere ao vínculo do agressor, constatou-se que são pessoas próximas à criança, tendo como principais perpetradores padrastos, pai, parentes.

No tocante a revelação, a mãe é a primeira fonte de ajuda que a criança recorre para contar sobre os abusos, em muitos casos na tentativa de resguardar o casamento, essa mãe nega os fatos e joga a responsabilização para a própria criança. Para Queiroz et al (2016), a violência sexual quase sempre é cometida no contexto familiar, geralmente, permanece impune na maioria dos casos, isso porque muitas vezes não é denunciada, seja pela criança, que tende a ter uma relação de confiança com o agressor, seja pelos familiares, que acobertam ou têm medo do que lhes possa acontecer.

Em consonância com essas informações o IACAS (2019) comenta que os fatores de risco dentro do contexto familiar que promovem a violência sexual seriam abuso de álcool e outras drogas, desemprego, falta de comunicação entre os membros, responsáveis passivos ou ausentes, dificuldades conjugais, famílias recompostas, pai ou mãe abusados ou negligenciados na sua infância e autoritarismo.

Em complemento a essa questão, Paulo e Saffioti (1997 apud ROMERO 2007), verificaram que dentre toda constelação de parentes investigados nos casos de violência sexual intrafamiliar, $71,5 \%$ dos agressores eram pais biológicos e 11,1\% padrastos. Reafirmando esse problema Habigzang e Caminha (2004, p.30) pontuam que "[...] os abusos sexuais incestuosos possuam maior impacto cognitivo-comportamental na criança. O incesto é, então, considerado um fator agravante para as consequências decorrentes de experiências sexualmente abusivas [...]".

Nesse viés, observa-se que a violência sexual contra crianças e adolescentes é um fenômeno que ocorre em maior proporção no âmbito intrafamiliar, e o crime é praticado 
com mais frequência por pessoas do gênero masculino. Porém, isso não significa que indivíduos do sexo feminino não pratiquem tal crime.

\subsection{Sintomas frequentes}

A partir do levantamento de sintomas frequentes em crianças vítimas de violência sexual, verificou-se que $17 \%$ dos sintomas mais frequente nas crianças vítimas de violência sexual foi dor abdominal, 13\% falta de apetite, $10 \%$ náuseas, vômitos, enjoos, $9 \%$ dor no peito, $6 \%$ enurese, $6 \%$ dor na genitália, $4 \%$ dor de cabeça, $3 \%$ encoprese, $1 \%$ infecção urinária, $1 \%$ desmaio, $32 \%$ não apresentaram sintomas ou o responsável não soube informar. Ressalta-se que no formulário oferecia-se a opção de apresentar mais de uma opção.

A violência sexual e suas múltiplas consequências na saúde das vítimas são principalmente uma violação dos direitos humanos, tais danos podem prejudicar essas crianças para o resto de suas vidas. De acordo com Soares (2016), as vítimas também enfrentam a possibilidade de adquirirem doenças sexualmente transmissíveis, e o risco de uma gravidez indesejada decorrente do abuso.

\footnotetext{
Os sintomas atingem todas as esferas de atividades, podendo ser simbolicamente a concretização, ao nível do corpo e do comportamento, daquilo que a criança ou o adolescente sofreu. Ao passar por uma experiência de violação de seu próprio corpo, elas reagem de forma somática independentemente de sua idade, uma vez que sensações novas foram despertadas e não puderam ser integradas. (PRADO, 2004, p. 64 apud FLORENTINO, 2015, p.140).
}

Dessa forma, pode-se compreender que a experiência causada pelo abuso sexual, à violação do corpo expressa uma invasão mais intensa. Pois é uma experiência que priva das crianças o direito de vivenciar emoções agradáveis de modo a apreenderem o mundo, e dar-lhes um significado que assegurem a identificação como atores sociais, capazes de serem reconhecidas pelos outros como sujeitos de direitos.

\subsection{Alterações do sono}

As alterações do sono apresentadas nas crianças vítimas de violência sexual foram $43 \%$ pesadelos, $32 \%$ insônia, $22 \%$ não apresentaram nenhuma alteração ou os responsáveis não informaram. 
Com a coleta de dados foi verificar que o sono das crianças vítimas de violência sexual também foi afetado, manifestando insônia e pesadelos ou terror noturno, essa alterações estão vinculadas na maioria das vezes pelo medo do agressor. Para Dalgalarrondo (2008), a insônia caracteriza-se pela dificuldade de adormecer, como também pelo despertar durante a madrugada, onde o indivíduo não consegue voltar a dormir, tal questão está ligada a quadros de ansiedade, tensão, preocupação. Os pesadelos são sonhos ansiosos, com conteúdos assustadores e terríficos, estão associados a conflitos emocionais, medos antigos e atuais. Verifica-se, portanto, alterações no sono das crianças, diante do medo e dos conflitos emocionais vivenciados por elas.

\subsection{Alterações psíquicas- medos}

Para a coleta de informações das alterações psíquicas frequentes em crianças e adolescentes vítimas de violência sexual disponibilizou-se a possibilidade de cada participante responder no sumário mais de uma opção. Logo, o número de respostas de alterações psíquicas apresenta-se superior ao número de sumários coletados.

Averiguou-se que $18 \%$ das crianças tem medo de serem violentadas, $18 \%$ tem medo de confiarem nas pessoas, $14 \%$ de serem abandonadas, $12 \%$ tem medo de morrer, $10 \%$ tem medo dos agressores, $10 \%$ tem medo de pessoas do sexo oposto, $9 \%$ tem medo de relacionarem, $7 \%$ tem medo de não serem aceitas, $3 \%$ não apresentaram alterações ou o responsável não soube informar.

Verificou-se que as crianças da pesquisa manifestaram alguns prejuízos nas suas relações interpessoais em decorrência à violência sofrida, a gravidade desses danos será determinada de como essa violência ocorreu, o tempo que durou, se foi incestuosa. Para Romero (2007), crianças vítimas de violência sexual possivelmente apresentarão algum transtorno. Entre esses efeitos encontram-se alterações nas esferas física, psicológica e social, tais como: distúrbios do sono, medo e dificuldades escolares. Em consonância com essa questão Silva (2000, p.32 apud FLORENTINO 2015, p. 142) aponta que

\footnotetext{
Os sintomas construídos durante uma experiência traumática afetam não somente os pensamentos do indivíduo, mas a sua memória, o estado de consciência e todo o campo de ação, de iniciativa e de objetividade na vida. Muitas vítimas criam uma área de proteção em volta de si que as impede de continuar com a vida normal. Uma vítima de violência
} 
física seja ela estupro ou pancadas evita sair de casa, tem medo de andar sozinha, rejeita sexo ou qualquer contato físico.

\subsection{Sentimentos frequentes}

No que tange aos sentimentos frequentes em crianças e adolescentes vítimas de violência sexual, disponibilizou-se a possibilidade de cada participante responder mais de um quesito de sentimentos manifestos. Verificou-se que $28 \%$ das crianças apresentaram raiva, $28 \%$ tristeza, $12 \%$ ansiedade, $10 \%$ desânimo, $7 \%$ angústia, $6 \%$ solidão, $2 \%$ baixa autoestima, $6 \%$ não apresentaram nenhuma alteração ou o responsável não soube responder.

Com base nas informações do presente estudo, observa-se que nenhuma criança reage igual à outra, assim algumas poderão desenvolver algum tipo de transtorno pela experiência traumática vivenciada, ou por outro lado elaborarem esse sofrimento de uma melhor maneira. Sobre essa questão Hohendorff (2017, p. 247), afirma que a violência sexual é um fator de risco para o desenvolvimento de sintomas e quadros psicopatológicos. Dessa forma, não existe uma síndrome, um conjunto de sinais e sintomas que seja exclusivamente manifestado pelas vítimas. O desenvolvimento de sintomas dependerá da propensão de cada indivíduo.

\subsection{Pensamentos frequentes}

Com referência aos pensamentos frequentes em crianças e adolescentes vítimas de violência sexual, disponibilizou-se a possibilidade de cada participante responder mais de um pensamento. Observou-se que $13 \%$ das crianças apresentaram ideias suicidas, $6 \%$ pensamento persecutório, $3 \%$ pensamento pessimista, $78 \%$ não apresentou alterações do pensamento, ou o responsável não informou.

Para Florentino (2015), aponta que os danos tardios podem se manifestar através de ocorrência e incidência de transtornos psiquiátricos como dissociação afetiva, pensamentos invasivos, ideação suicida e fobias mais agudas, isolamento e hostilidade; sensação crônica de perigo e confusão, cognição distorcida, imagens distorcidas do mundo e dificuldade de perceber a realidade. Em concordância Ballone (2003 apud SOARES et al. 2016, p. 88), também afirma que "a criança abusada sexualmente, principalmente por familiares ou pessoas significativas, desenvolve a perda da autoestima, torna-se retraída, perde a confiança nos adultos e pode até chegar a considerar

Educação, Psicologia e Interfaces, Volume 4, Número 1, p. 144-159, Janeiro/Março, 2020.

ISSN: 2594-5343. DOI: https://doi.org/10.37444/issn-2594-5343.v4i1.194 
o suicídio". Diante desses dados, pode-se verificar que a violência sexual contra crianças muitas vezes gera desordem cognitiva, além de acarretar culpabilidade colocando essas vítimas em potencial risco para cometer suicídio.

\subsection{Comportamentos frequentes}

Com base nas informações investigadas, os comportamentos frequentes em crianças e adolescentes vítimas de violência sexual, disponibilizou-se a possibilidade de cada participante responder mais de uma opção. Constatou-se que $19 \%$ das crianças manifestaram agressividade, $17 \%$ choro, $13 \%$ inquietação, $6 \%$ autoflagelação, $6 \%$ fuga de casa, $6 \%$ regressão comportamental, $6 \%$ distúrbio alimentar, $4 \%$ lentidão, $4 \%$ apatia, $2 \%$ isolamento, $1 \%$ tentativas de suicídio, $15 \%$ não apresentaram alterações ou, o responsável não informou. É relevante frisar, que muitos desses comportamentos é uma forma da criança externalizar o que está acontecendo com elas, como não conseguem muitas vezes verbalizar o que estão sentindo.

Para Schaefer (2018, p.1140) "[...] o abuso sexual tem sido associado tanto a sintomas externalizantes (comportamentos delinquentes e agressividade) quanto a sintomas internalizantes (depressão, ansiedade, isolamento, dificuldades de atenção e queixas somáticas)". Verifica-se, então, que as consequências resultantes da violência sexual são profundas e marcarão indelevelmente a vida da vítima.

\subsection{Anormalidades sexuais}

Sobre as anormalidades sexuais em crianças e adolescentes vítimas de violência sexual, disponibilizou-se a possibilidade de cada participante responder mais de uma opção. Verificou-se que $6 \%$ das crianças apresentaram masturbação, $3 \%$ comportamento sedutor, $3 \%$ necessidade de estímulo sexual, $1 \%$ introdução de objetos na genitália, $87 \%$ os responsáveis não informaram ou não apresentaram alterações.

Vale destacar, a dificuldade dos responsáveis pelas crianças em verbalizarem sobre essa questão, ou não souberam informar a ocorrência de algum comportamento sexual anormal. Assim, fica evidente que o tema sexualidade ainda é cercado de tabus, principalmente nos casos de violência em que a família fica totalmente desestruturada. 
É necessário compreender que a sexualidade forma a parte integral da personalidade de cada indivíduo, ou seja, é uma necessidade básica e um aspecto do ser humano que não pode ser dissociado de outros, sendo imprescindível ser ensinada para as crianças. Santos (2011, p. 80), afirma que algumas crianças podem apresentar incapacidade de diferenciar sexo de afeto, ou fazer confusão entre amor parental e manifestações sexuais e compulsão sexual, como tentativa de se sentirem amadas e adequadas socialmente.

Em consonância, Schaefer (2018, p.1469), aponta os comportamentos sexuais inadequados nas crianças vítimas de violência sexual, tais como querer tocar as genitais de outras pessoas, demonstrarem interesse e conhecimento sexual avançado para a sua fase de desenvolvimento, masturbação frequente e muitas vezes na frente de outros sujeitos, preocupações de cunho sexual. A partir desses dados verifica-se que os abusos sexuais além de serem crimes, levam a criança a conhecer de forma precoce sensações sexuais, pela imaturidade essas crianças compreendem essas sensações como forma de carinho. É importante destacar, que as crianças que sofrem violência sexual manifestam comportamentos eróticos, brincadeiras sexualizadas, que sinalizam o que estão vivenciando.

\subsection{Vida escolar}

No que tange a vida escolar, disponibilizou-se a possibilidade de cada participante responder mais de uma opção, assim o número de respostas é superior aos sumários. Observou-se que 14\% das crianças apresentaram rendimento baixo, 9\% desinteresse pelos estudos, $7 \%$ dificuldade de concentração, 6\% dificuldade de aprendizado, 6\% atenção dispersa, 4\% evasão escolar, 3\% reprovação, 51\% não apresentaram alterações na vida escolar.

Os dados também evidenciaram prejuízos na vida escolar dessas crianças, decorrente dos abusos sexuais. De alguma maneira, crianças que estão vivenciando situações de violência apresentam os sinais e sintomas, e emitem mesmo de uma forma não verbal o pedido de ajuda. Nesse sentido, é cada vez mais urgente a necessidade de conhecimento do assunto para a identificação da violência contra crianças e adolescentes por parte da escola, com o objetivo de não só enfrentar e combater, mas de prevenir e resguardar as crianças. Para Jurema e Neri (2015, p.339), “contribuir para a efetivação

Educação, Psicologia e Interfaces, Volume 4, Número 1, p. 144-159, Janeiro/Março, 2020.

ISSN: 2594-5343. DOI: https://doi.org/10.37444/issn-2594-5343.v4i1.194 
desses direitos é, também, função social da instituição que é responsável, junto com a família, o Estado e toda a sociedade, pelo desenvolvimento pleno da criança: a escola".

Em consonância com a hipótese da pesquisa, a análise dos documentos demonstraram que as crianças vítimas de abusos sexuais apresentaram alterações físicas, psíquicas, emocionais, comportamentais, sociais, anormalidades sexuais, prejuízo escolar. De acordo com Florentino (2015, p. 140), "as consequências do abuso sexual infanto-juvenil estão presentes em todos os aspectos da condição humana, deixando marcas físicas, psíquicas, sociais, sexuais, entre outras que poderão comprometer seriamente a vida da vítima”.

Os fatores de risco que propiciam a violência são múltiplos, como uso de substâncias psicoativas na família, falta de comunicação no contexto familiar, desemprego, dificuldades conjugais, responsáveis passivos, famílias recompostas. Porém, é de suma importância mencionar que questões estruturais como economia, educação, criação de políticas públicas efetivas são um dos pontos mais relevantes para enfrentamento, combate e prevenção da violência sexual, ou seja, a análise tem que ser micro e macrossocial.

Para Santos (2011, p.15) afirma que a violação sexual é um intento à sobrevivência, ao bem-estar e ao futuro de crianças e adolescentes e pode trazer graves consequências para seu desenvolvimento, sua saúde e sua capacidade de aprendizagem. Portanto, fica evidente que crianças e adolescentes são mais suscetíveis à violência sexual pelo simples fato de serem crianças e adolescentes.

\section{CONSIDERAÇÕES FINAIS}

Para realização dessa pesquisa ocorreu uma notável dificuldade em quantificar a frequência da violência sexual contra crianças e adolescentes, não sendo possível mensurar a magnitude do problema. Atualmente, no Brasil não existe um banco de dados geral que mensure as denúncias registradas por todas as fontes possíveis, ou seja, não há controle consistente e padronizado em nível federal, estadual ou municipal que acompanhe as denúncias, se eram procedentes, quantas se tornaram inquéritos policiais, quantas chegaram à Justiça ou o que aconteceu com as crianças. Isso também acontece pelo fato de que muitos casos de abusos sexuais não são denunciados. 
Quando a violência sexual ocorre com as crianças o número de denúncias pode ser ainda menor, uma vez que a própria criança pode não revelar aos seus responsáveis, ou até mesmo pelo motivo do adulto não acreditar no relato da criança. $\mathrm{O}$ abuso sexual cometido no âmbito familiar acarreta maiores dificuldade na denuncia do agressor em consequência dos prejuízos que a família sofrerá.

$\mathrm{Na}$ análise dos documentos foram encontrados alguns obstáculos, tais como falta de informações nos materiais, ou a dificuldade dos responsáveis verbalizarem ou não saberem informar às alterações que as crianças estavam vivenciando depois da violência sexual.

Diante dos dados constatados através dessa pesquisa, fica evidente a relevância do assunto e a necessidade de mais engajamento na criação de novos estudos sobre a violência sexual contra crianças e adolescentes. Pois, foi possível observar os obstáculos, negligências por parte do estado, da sociedade e da família quanto à proteção integral das crianças e adolescentes, ou seja, o caminho é longo e cercado de desafios.

\section{REFERÊNCIAS BIBLIOGRÁFICAS}

BRASIL. Lei no 8.069, de 13 de julho de 1990. Dispõe sobre o Estatuto da Criança e do Adolescente e dá outras providências. Disponível em:

<http://www.planalto.gov.br/ccivil_03/leis/L8069.htm>. Acesso em: 25 de maio, 2019.

DALGALARRONDO, P. Psicopatologia e semiologia dos transtornos mentais. ed. 2. Porto Alegre: Artmed, 2008. 440 p.

HABIGZANG, L.F; CAMINHA, R.M. Abuso sexual contra crianças e adolescentes: conceituação e intervenção clínica. São Paulo: Casa do Psicólogo, 2004. p.173.

HOHENDORFF, J. V; PATIAS, N. D. Violência sexual contra crianças e adolescentes: identificação, consequências e indicações de manejo. Barbarói, Santa Cruz do Sul, n.49, p., jan./jun. 2017.

MINAYO, M.C.S. Violência e saúde. Rio de Janeiro: Editora FIOCRUZ, 2006. p.132.

PONCE, B.J; NERI, J. F.O currículo escolar em busca da justiça social: a violência doméstica contra a criança e o adolescente. Revista e-Curriculum, São Paulo, v. 13, n. 02, p. 331-349. abr./jun. 2015.

RODRIGUES, B. S. Guia escolar: identificação de sinais de abuso e exploração sexual de crianças e adolescentes. Seropédica, RJ: EDUR, 2011. p.242. 
ROMERO, K. R. P. S. Crianças vítimas de abuso sexual: aspectos psicológicos da dinâmica familiar. Ministério Público do Estado do Paraná. Curitiba-Paraná. 2007. p.127.

SÁ, C. M. Q. et al. Abuso sexual infantil e suas consequências na vida adulta da mulher - uma abordagem reflexiva. Mostra Interdisciplinar do curso de Enfermagem. v. 2, Jun. 2016.

SCHAEFER, L. S. et al. Indicadores Psicológicos e Comportamentais na Perícia do Abuso Sexual Infantil. Trends Psychol. Ribeirão Preto, v. 26, n. 3, p. 1467-1482, Set. 2018.

SECRETARIA DE VIGILÂNCIA EM SAÚDE. Análise epidemiológica da violência sexual contra crianças e adolescentes no Brasil, 2011 a 2017. Ministério da saúde. Secretaria de vigilância em saúde. Boletim Epidemiológico. v.49, n.27, Jun. 2018.

SOARES, E. M. R. et al. Perfil da violência sexual contra crianças e adolescentes. Revista Interd. v. 9, n. 1, p. 87-96, jan/mar. 2016.

SOARES, L. G. et al. Violações por violência de direitos fundamentais de crianças e adolescentes. Rev Rene. v.18, n.6 , p. 734-741, nov/dez. 2017

SOUZA, A.C.F. Projeto Mobilizar e Agir. Manaus: IACAS, 2019. p. 45.

VIEIRA, M. S. A interface entre a violência sexual contra crianças e adolescentes e a violência de gênero: notas críticas acerca do cenário do município de Porto Alegre.

Revista Imagem Interdisciplinar. v. 9, n. 12 , p. 254-269, 2015.

\section{Credenciais da autora}

SILVA, Dayane Monteiro da. Possui graduação em Psicologia Centro Universitário Fametro/Brasil. E-mail: dayanemonteyro12@gmail.com

Endereço para correspondência: Dayane Monteiro da Silva. E-mail: dayanemonteyro12@gmail.com

Como citar este artigo (Formato ABNT): SILVA, Dayane Monteiro da. O perfil psicossocial de crianças e adolescentes vítimas de violência sexual. Educação, Psicologia e Interfaces, v. 4, n. 1, p. 144-159, 2020. DOI: https://doi.org/10.37444/issn2594-5343.v4i1.194

Recebido: $21 / 10 / 2019$

Aceito: 28/11/2019 